\title{
A EDUCAÇÃO ESTATÍSTICA NOS ANOS INICIAIS DO ENSINO FUNDAMENTAL: ESTADO DA ARTE
}

\author{
THE EDUCATION STATISTICS IN THE EARLY YEARS OF ELEMENTARY \\ SCHOOL: STATE OF THE ART
}

\author{
Ailton Paulo de Oliveira Júnior ${ }^{1}$ \\ Márcia Lopes Vieira ${ }^{2}$
}

\begin{abstract}
RESUMO
Este estudo apresenta um Estado da Arte de pesquisas sobre a Educação Estatística nos anos iniciais do Ensino Fundamental, tomando por base o banco de teses e dissertações da Sociedade Brasileira de Educação Matemática (SBEM), do período de 2003 a 2007. Foram encontradas 04 (quatro) teses e 05 (cinco) dissertações relacionadas ao tema da investigação. As pesquisas foram levantadas com o objetivo de realizar uma reflexão crítica acerca de aspectos que permeiam as atuais discussões sobre a importância da Educação Estatística no mundo atual, especificamente, nos anos iniciais do Ensino Fundamental. Em relação ao professor polivalente, que ministra essa e várias outras disciplinas, tais mudanças envolvem elementos que merecem destaques: formação, concepções, atitudes, saberes, experiências e outros que estão estritamente relacionados com a prática pedagógica do professor polivalente. Para que os pressupostos contidos nos Parâmetros Curriculares Nacionais (PCN) sejam alcançados requer compromisso individual, coletivo, político e institucional para que de fato a sociedade usufrua de uma educação com qualidade. Desta forma acredita-se na importância de ampliar os estudos, pesquisas, reflexões, discussões e ações de modo a contribuir com a inserção da Estatística não apenas nos currículos, mas principalmente na prática cotidiana dos docentes.
\end{abstract}

Palavras-chave: Estado da arte. Estatística. Anos iniciais do Ensino Fundamental.

\begin{abstract}
This study presents a state of the art of research on Education Statistics in the early years of elementary school, building on the bench of theses and dissertations of the Brazilian Society of Mathematical Education for the period 2003-2007. It was found four (04) theses and five (05) dissertations related to the topic of research. Surveys were raised in order to carry out a critical analysis of factors that underlie current discussions about the importance of teaching statistics in the world today, especially in the early years of elementary school. Regarding versatile teacher, who teaches this and various other disciplines, such changes involve elements that deserve highlights: training, conceptions, attitudes, knowledge, experiences and others that are strictly related to the pedagogical practice of versatile teacher. For the assumptions contained in the Parâmetros Curriculares Nacionais (PCN) are achieved requires individual, collective, political and institutional commitment to actually enjoy the company of a quality education. Thus, we believe in the importance of extending the studies, research, reflections, discussions and actions to contribute to the integration of statistics not only in the curriculum, but mostly in the daily practice of teachers.
\end{abstract}

Key-words: State of the art. Statistics. Early years of elementary school.

\footnotetext{
${ }^{1}$ Docente no Programa de Pós-Graduação em Educação. Universidade Federal do Triângulo Mineiro UFTM. E-mail: drapoj@uol.com.br

${ }^{2}$ Programa de Pós-Graduação em Educação. Universidade Federal do Triângulo Mineiro - UFTM. Instituto

Federal de Educação, Ciência e Tecnologia do Triângulo Mineiro - IFTM. E-mail: marcialopes@iftm.edu.br
} 


\section{Introdução}

O Ensino de Estatística preconizado nos Parâmetros Curriculares Nacionais (PCN) é abordado num bloco denominado de Tratamento da Informação. Na sociedade contemporânea, em constante transformação, esse conteúdo é considerado como fator fundamental para que o cidadão possa atuar criticamente diante dos desafios, escolhas e decisões.

De acordo com os PCN (1997, p. 25) "para exercer a cidadania, é necessário saber calcular, medir, raciocinar, argumentar, tratar informações estatisticamente, etc.”. No que concerne, especificadamente, com a Estatística este documento legal prevê que a finalidade é

[...] fazer com que o aluno venha a construir procedimentos para coletar, organizar, comunicar e interpretar dados, utilizando tabelas, gráficos e representações que aparecem frequentemente em seu dia-a-dia". (BRASIL, 1997, p. 56)

Desta forma, os professores têm o desafio de trabalhar os elementos de estatística e também os de combinatória e probabilidade desde os ciclos iniciais para que os alunos saibam utilizar as diferentes fontes de informações para adquirir conhecimentos.

Já no campo científico, nota-se nas últimas décadas que o ensino de Estatística vem sendo mais valorizado, sobretudo pelo engajamento e colaboração por parte de profissionais atuantes e pesquisadores da área que proporcionam um crescimento de publicações desta temática. Nessa perspectiva, o ensino de Estatística nos anos iniciais do Ensino Fundamental constitui o cerne da abordagem exposta ao longo deste texto.

A indagação que desencadeou este estudo foi: o que as pesquisas e estudos atuais têm apontado em relação ao ensino da Estatística nos anos iniciais do Ensino Fundamental? Em busca de uma boa fundamentação teórica subsidiada por pesquisas científicas recorreu-se ao site da Sociedade Brasileira de Educação Matemática - SBEM fazendo um recorte dos trabalhos desenvolvidos a partir de 2000 no banco de teses e dissertações que tratam do objeto de estudo aqui proposto. É oportuno esclarecer que a SBEM tem como finalidade buscar meios para desenvolver a formação matemática de todo cidadão do Brasil e também tem como objetivo difundir amplamente as informações e conhecimentos nas inúmeras vertentes da Educação Matemática. 
Sendo assim, verificou-se a necessidade de construir um Estado da Arte, no intuito de compreender quais aspectos relacionados à Educação Estatística nos anos iniciais do Ensino Fundamental estão sendo pesquisados. De acordo com Ferreira (2002) as pesquisas do tipo Estado da Arte podem ser compreendidas,

como de caráter bibliográfico, elas parecem trazer em comum o desafio de mapear e de discutir uma certa produção acadêmica em diferentes campos do conhecimento, tentando responder que aspectos e dimensões vêm sendo destacados e privilegiados em diferentes épocas e lugares, de que formas e em que condições têm sido produzidas certas dissertações de mestrado, teses de doutorado, publicações em periódicos e comunicações em anais de congressos e de seminários (FERREIRA, 2002, p. 258).

Vale ressaltar que este tipo de pesquisa não é somente fazer o levantamento do material que já foi produzido e publicado a respeito de determinada temática, mas sim realizar um diagnóstico e uma avaliação de forma crítica do que foi pesquisado e analisado.

Assim, investigar o que tem sido produzido sobre o tema apresentado faz-se fundamental, uma vez que as produções científicas visam à construção de novos conhecimentos que poderão servir de base para melhorias nas práticas de ensino.

\section{Procedimentos metodológicos do Estado da Arte em Estatística nos anos iniciais do Ensino Fundamental}

Após situar brevemente sobre a problemática em questão e diante da relevância educacional e social da Estatística para o cidadão, adota-se neste estudo uma abordagem bibliográfica dos resumos publicados em teses e dissertações disponibilizados pelo sítio da Sociedade Brasileira de Educação Matemática - $\mathrm{SBEM}^{3}$.

Fundada em 27 de janeiro de 1988, a SBEM é uma sociedade civil, de caráter científico e cultural, sem fins lucrativos e sem qualquer vínculo político, partidário ou religioso. Tem como finalidade congregar profissionais da área de Educação Matemática e de áreas afins. A SBEM tem em seus quadros pesquisadores, professores e alunos que

\footnotetext{
${ }^{3}$ http://www.sbem.com.br/gt 12/publicacoes/publicacoes.htm
} 
atuam nos diferentes níveis do sistema educacional brasileiro, da educação básica à educação superior ${ }^{4}$.

O grupo de trabalho denominado GT 12 - Ensino de Estatística e Probabilidade tem por objetivo ter um local onde interessados na melhoria do Ensino de Estatística e de Probabilidade, em todos os níveis, possam transitar e encontrar: eventos, ideias, organizações, publicações e pesquisadores do assunto. Nas publicações específicas deste grupo foram encontradas 30 (trinta) dissertações e 12 (doze) teses que após a leitura dos resumos, houve um recorte para cinco dissertações $(16,67 \%)$ e 04 teses $(33,33 \%)$ que tratavam da Educação Estatística nos anos iniciais do Ensino Fundamental.

Nesse sentido, esta pesquisa possui natureza metodológica bibliográfica, com revisão de literatura. Segundo Gil (2010) este tipo de categorização é útil por permitir ao investigador uma boa amplitude de fenômenos.

A pesquisa também apresenta uma abordagem qualitativa que na visão de González Rey (1998),

substitui a resposta pela construção, a verificação pela elaboração e a neutralidade pela participação. $\mathrm{O}$ investigador entra no campo com o que lhe interessa investigar, no qual não supõe o encerramento no desenho metodológico de somente aquelas informações diretamente relacionadas com o problema explícito a priori no projeto, pois a investigação implica a emergência do novo nas ideias do investigador, processo em que a o marco teórico e a realidade se integram e se contradizem de formas diversas no curso da produção teórica. (GONZÁLEZ REY, 1998, p. 42).

A partir da metodologia de pesquisa utilizada foram construídos os Quadros 1 e 2 com a caracterização das 9 (nove) publicações selecionadas, de 2003 a 2007.

Quadro 1 - Apresentação das dissertações selecionadas e suas caracterizações.

\begin{tabular}{|c|c|c|c|}
\hline Título & Autor & Ano & Instituição \\
\hline $\begin{array}{c}\text { O desenvolvimento de conceitos } \\
\text { elementares do bloco Tratamento da } \\
\text { Informação com o auxílio do ambiente } \\
\text { computacional: um estudo de caso com } \\
\text { uma professora do } 1^{\circ} \text { e } 2^{\circ} \text { ciclos do } \\
\text { Ensino Fundamental }\end{array}$ & Sandra da Silva Santos & 2003 & PUC / SP \\
\hline $\begin{array}{c}\text { As concepções dos professores de } \\
\text { Matemática sobre o uso de modelagem no } \\
\text { desenvolvimento do raciocínio }\end{array}$ & $\begin{array}{c}\text { Claudinei Aparecido } \\
\text { da Costa }\end{array}$ & 2003 & PUC / SP \\
\hline
\end{tabular}

\footnotetext{
${ }^{4} \mathrm{http}: / /$ www.sbembrasil.org.br/sbembrasil/sociedade.html
} 


\begin{tabular}{|c|c|c|c|}
\hline combinatório no Ensino Fundamental & 2004 & PUC / SP \\
\hline $\begin{array}{c}\text { Concepções de professores e o Ensino da } \\
\text { Probabilidade na escola básica }\end{array}$ & $\begin{array}{c}\text { Mauro César } \\
\text { Gonçalves }\end{array}$ & 2004 & PUC / SP \\
\hline $\begin{array}{c}\text { Introduzindo a Estatística nas séries } \\
\text { iniciais do Ensino Fundamental a partir de } \\
\text { material manipulativo: uma intervenção de } \\
\text { ensino }\end{array}$ & $\begin{array}{c}\text { Simone da Silva Dias } \\
\text { Caetano }\end{array}$ & 2006 & UNICAMP \\
\hline $\begin{array}{c}\text { Trabalho de Projetos: possibilidades e } \\
\text { desafios na formação Estatística do } \\
\text { pedagogo }\end{array}$ & Jefferson Biajone \\
\hline
\end{tabular}

Quadro 2 - Apresentação das teses selecionadas e suas caracterizações.

\begin{tabular}{|c|c|c|c|}
\hline Título & Autor & Ano & Instituição \\
\hline $\begin{array}{c}\text { Gráficos de barras e materiais } \\
\text { manipulativos: analisando dificuldades e } \\
\text { contribuições de diferentes representações } \\
\text { no desenvolvimento da conceptualização } \\
\text { matemática em crianças de seis a oito anos }\end{array}$ & $\begin{array}{c}\text { Ana Coelho Vieira } \\
\text { Selva }\end{array}$ & 2003 & UFPE \\
\hline $\begin{array}{c}\text { O conhecimento profissional dos } \\
\text { professores e suas relações com estatística } \\
\text { e probabilidade na Educação Infantil }\end{array}$ & $\begin{array}{c}\text { Celi Aparecida } \\
\text { Espasandin Lopes }\end{array}$ & 2003 & UNICAMP \\
\hline $\begin{array}{c}\text { O processo de aprender noções de } \\
\text { Probabilidade e suas relações no cotidiano } \\
\text { das séries iniciais do Ensino Fundamental: } \\
\text { uma história de parceria }\end{array}$ & Paulo César Oliveira & 2003 & UNICAMP \\
\hline $\begin{array}{c}\text { A Educação Estatística: uma investigação } \\
\text { acerca dos aspectos relevantes à didática da } \\
\text { Estatística em cursos de Graduação }\end{array}$ & Celso Ribeiro Campos & 2007 & UNESP \\
\hline
\end{tabular}

\section{Análise e discussão}

$\mathrm{Na}$ dissertação de Santos (2003) realizada na Pontifícia Universidade Católica de São Paulo (PUC-SP), junto ao Programa de Pós-Graduação em Educação Matemática, orientada pelo Prof. Dra. Sandra Maria Pinto Magina, “O desenvolvimento de conceitos elementares do bloco Tratamento da Informação com o auxílio do ambiente computacional: um estudo de caso com uma professora do $1^{\circ}$ e $2^{\circ}$ ciclos do Ensino 
Fundamental" mostramos a problemática, o objetivo principal e os possíveis encaminhamentos para estudos futuros:

1) Problemática

$\checkmark$ Como o professor de Matemática está instrumentalizado para ensinar Combinatória no Ensino Fundamental?

$\checkmark$ Quais as concepções do professor que influenciam sua prática pedagógica, e como uma formação continuada pode alterar ou reforçar estas concepções?

2) Objetivos

$\checkmark$ Analisar e estudar os instrumentos disponíveis para o professor trabalhar com a introdução do raciocínio combinatório no Ensino Fundamental por processo de modelagem.

3) Conclusões e direcionamentos

$\checkmark$ O uso da Modelagem como instrumento de um processo de ensino permite ao aluno construir o significado do conceito que lhe é apresentado; este deve reconhecer e selecionar as características do fenômeno que são pertinentes ao modelo e assim estará apto a reconhecer estas características em outras situações.

$\checkmark$ Nos livros didáticos não existe a preocupação em definir formalmente o raciocínio combinatório;

$\checkmark$ O professor não possui satisfatoriamente o conhecimento matemático para ensinar Combinatória.

$\mathrm{Na}$ dissertação de Costa (2003) realizada na Pontifícia Universidade Católica de São Paulo (PUC-SP), junto ao Programa de Pós-Graduação em Educação Matemática, orientada pelo Prof. Dra. Cileda de Queiroz e Silva Coutinho, “As concepções dos professores de Matemática sobre o uso de modelagem no desenvolvimento do raciocínio combinatório no Ensino Fundamental" mostramos a problemática, o objetivo principal e os possíveis encaminhamentos para estudos futuros:

1) Problemática 
$\checkmark$ Como se dá o processo de formação e desenvolvimento de conceitos matemáticos referentes ao bloco de conteúdos Tratamento da Informação por parte do professor, com auxílio do ambiente computacional?

2) Objetivos

$\checkmark$ Investigar as possibilidades oferecidas pelo ambiente computacional do tabletop no processo de formação dos conhecimentos elementares de Estatística.

3) Conclusões e direcionamentos

$\checkmark$ A pesquisa constatou que a situação do ensino brasileiro, especialmente no caso da Matemática é paradoxal, existem bons materiais de apoio; os parâmetros norteadores (Parâmetros Curriculares Nacionais - Ensino Fundamental) os livros didáticos e a proposta curricular estadual, no entanto o professor não conhece os Parâmetros suficientemente e, ainda, o que é mais grave, não conhece o objeto matemático (Análise Combinatória) o suficiente para que possa ensiná-lo aos seus alunos, seja por meio da Modelagem ou não.

$\checkmark$ Quanto aos conhecimentos mínimos que o professor deve ter para ensinar Combinatória no ensino Médio ou Fundamental é o conhecimento matemático e que nós constatamos que ele não o possui satisfatoriamente.

$\checkmark$ Para pesquisas futuras é sugerido investigar quais outros conhecimentos mínimos devem ser mobilizados pelo professor (em Combinatória ou em outro assunto) para ensina-los de maneira satisfatória no Ensino Fundamental. Isto pode se dar por meio da observação da prática dos professores, entrevistas ou análise quantitativa do desempenho dos professores nos cursos de formação continuada, ou ainda um estudo clínico sobre a formação do professor, analisando sua passagem por um curso de formação continuada e os resultados dessa formação.

Na dissertação de Gonçalves (2004) realizada na Pontifícia Universidade Católica de São Paulo (PUC-SP), junto ao Programa de Pós-Graduação em Educação Matemática, orientada pelo Prof. Dra. Cileda de Queiroz e Silva Coutinho, “Concepções de professores 
e o Ensino da Probabilidade na escola básica" mostramos a problemática, o objetivo principal e os possíveis encaminhamentos para estudos futuros:

1) Problemática

$\checkmark$ Há relação entre o que os professores de Matemática, hoje em exercício, apreenderam quando foram alunos do Ensino Básico e suas concepções atuais sobre a Aleatoriedade e Probabilidade?

2) Objetivos

$\checkmark$ Identificar as concepções atuais dos professores de Matemática em exercício no Ensino Fundamental sobre Probabilidade e verificar se há relação entre estas concepções e as diferentes tendências do Ensino de Probabilidade nas décadas de 70,80 e 90 .

3) Conclusões e direcionamentos

$\checkmark$ Há indícios de haver uma relação mais pragmática, ou seja, a concepção atual sobre Probabilidade pode estar relacionada à atuação profissional do Professor nas séries e ao tempo em que atua;

$\checkmark$ Os professores operam mudanças em concepções e alterações em sua prática pedagógica.

$\checkmark$ O uso da Modelagem como instrumento de um processo de ensino permite ao aluno construir o significado.

Na dissertação de Caetano (2004) realizada na Pontifícia Universidade Católica de São Paulo (PUC-SP), junto ao Programa de Pós-Graduação em Educação Matemática, orientada pelo Prof. Dra. Sandra Maria Pinto Magina, "Introduzindo a Estatística nas séries iniciais do Ensino Fundamental a partir de material manipulativo: uma intervenção de ensino" mostramos a problemática, o objetivo principal e os possíveis encaminhamentos para estudos futuros:

1) Problemática 
$\checkmark$ Quais as contribuições de uma intervenção de ensino com o uso de material manipulativo para o ensino-aprendizagem de conceitos elementares de Estatística nas séries iniciais do Ensino Fundamental?

2) Objetivos

$\checkmark$ Investigar o desenvolvimento da leitura e interpretação de gráficos e o conceito de média aritmética por crianças da quarta série do Ensino Fundamental por meio de material manipulativo.

3) Conclusões e direcionamentos

$\checkmark$ A intervenção com o material manipulativo contribuiu para o ensino-aprendizagem de conceitos elementares de Estatística a alunos das séries iniciais do Ensino Fundamental ao proporcionar-lhes situações de leitura e interpretação de gráficos;

$\checkmark$ Sugere-se pesquisa com alunos de duas ou três escolas distintas e com maior tempo de aplicação do material manipulativo.

$\mathrm{Na}$ dissertação de Biajone (2006) realizada na Universidade de Campinas (UNICAMP), junto ao Programa de Pós-Graduação em Educação, orientada pelo Prof. Dra. Dione Lucchesi de Carvalho, "Trabalho de Projetos: possibilidades e desafios na formação Estatística do pedagogo" mostramos a problemática, o objetivo principal e os possíveis encaminhamentos para estudos futuros:

1) Problemática

$\checkmark$ Que contribuições didático-pedagógicas o trabalho de projetos pode trazer para a formação estatística do aluno da Pedagogia?

$\checkmark$ Que Estatística seria útil ao pedagogo para que ele pudesse reaplicá-la na sua vida profissional?

$\checkmark$ Que cidadania esta formação poderia propiciar e de que forma isto seria feito?

2) Objetivos

$\checkmark$ Estudar a intervenção que analisa as potencialidades e possibilidades didáticopedagógicas da abordagem do trabalho de projetos na formação estatística do pedagogo administrador escolar. 
3) Conclusões e direcionamentos

$\checkmark$ A Estatística assume uma função primordial para o exercício desta profissão, uma vez que o cotidiano profissional do administrador escolar é permeado por um sem número de aspectos relativos a organização da instituição escolar que são passíveis de manipulação estatística;

$\checkmark$ Convívio e interdependência equilibrados entre trabalhar com projetos enquanto processo de investigação onde questões são propostas, dados são interpretados, e resultados são comunicados e os processos dos cálculos, procedimentos e algoritmos, que se poderá proporcionar ao aluno da Pedagogia uma formação estatística equilibrada e à altura de suas necessidades pessoais e profissionais.

$\mathrm{Na}$ tese de doutorado realizada na Universidade Federal de Pernambuco junto ao Programa de Pós-Graduação em Psicologia - área de concentração: Psicologia Cognitiva e orientada pelo Prof. Dr. Jorge Tarcísio da Rocha Falcão, de Selva (2003), “Gráficos de barras e materiais manipulativos: analisando dificuldades e contribuições de diferentes representações no desenvolvimento da conceptualização matemática em crianças de seis a oito anos", indicamos a problemática, o objetivo principal e os possíveis encaminhamentos para estudos futuros:

\section{1) Problemática}

$\checkmark$ Dificuldades relatadas na literatura na compreensão de gráficos através de situações que estimulam a reflexão das crianças.

2) Objetivos

$\checkmark$ Investigar o uso de gráficos de barras como suporte representacional na resolução de problemas aditivos e as dificuldades surgidas na interpretação e construção dessa representação e avaliar se a combinação entre a representação gráfica e o uso de material manipulativo poderia auxiliar crianças a resolverem problemas aditivos envolvendo gráficos.

3) Conclusões e direcionamentos 
$\checkmark$ Os estudos realizados mostraram que a combinação entre gráficos de barras e problemas verbais com blocos pode ser um caminho promissor para o trabalho com gráficos, especialmente com crianças pequenas. Esta combinação parece auxiliar as crianças a relacionarem a representação gráfica com estratégias mais familiares de resolução de problemas;

$\checkmark$ Sugere-se inserir problemas de mesmo tipo dos trabalhados, mas com variações no lugar da incógnita e realizar entrevistas individuais com algumas crianças após o pós-teste para investigar mais profundamente o processo de raciocínio utilizado.

$\mathrm{Na}$ tese de Lopes (2003) realizada na Universidade de Campinas - UNICAMP junto ao Programa de Pós-Graduação em Educação orientada pelo Prof. Dra. Anna Regina Lanner de Moura, "O conhecimento profissional dos professores e suas relações com Estatística e Probabilidade na Educação Infantil", indicamos também os mesmos elementos, ou seja, a problemática, o objetivo principal e os possíveis encaminhamentos para estudos futuros:

1) Problemática

$\checkmark$ Que conhecimentos didáticos acerca da Probabilidade e da Estatística possui o professor da Educação infantil?

$\checkmark$ Como o professor reflete, epistemologicamente, sobre as idéias Estocásticas fundamentais?

$\checkmark$ Como o estudo, a vivência e a reflexão coletiva acerca do conteúdo estocástico e sua didática influenciam o conhecimento profissional e a prática do professor da Educação infantil?

2) Objetivos

$\checkmark$ Analisar se o estudo, a vivência e a reflexão sobre conceitos de Estatística e Probabilidade pode trazer elementos efetivos para o desenvolvimento profissional e a prática pedagógica de um grupo de professoras da Educação infantil.

3) Conclusões e direcionamentos 
$\checkmark$ O conhecimento curricular apareceu associado às concepções das professoras sobre o significado que a Estatística e a Probabilidade pode ter no desenvolvimento infantil, pois percebeu-se que .as professoras apresentaram clareza dos objetivos curriculares da Educação Infantil, elaborando propostas inseridas nos contextos dos projetos integrados de área.

$\checkmark \mathrm{O}$ conhecimento didático das professoras em relação à Matemática manifestou-se fortemente, na elaboração de problemáticas e na diversidade de estratégias de soluções.

$\checkmark$ O desenvolvimento profissional ampliou-se, através do trabalho efetivado, com ética e solidariedade, na produção conjunta dos conhecimentos conceituais e didáticos da Matemática e da Estatística.

$\checkmark$ Dessa forma, a autora defende um processo de formação que valorize o saber dessas educadoras, que provoque reflexão sistemática sobre as questões em curso, que as habilite a serem pesquisadoras de suas próprias práticas e que lhes dê condições para investirem na produção coletiva do conhecimento.

$\mathrm{Na}$ tese de Oliveira (2003) também realizada na Universidade Estadual de Campinas - UNICAMP junto ao Programa de Pós-Graduação em Educação orientada pelo Prof. Dra. Dione Lucchesi de Carvalho, “O processo de aprender noções de Probabilidade e suas relações no cotidiano das séries iniciais do Ensino Fundamental: uma história de parceria" indicamos os mesmos elementos:

\section{1) Problemática}

$\checkmark$ Que saberes docentes foram mobilizados por duas professoras envolvidas com o estudo de noções elementares pertinentes à Probabilidade?

$\checkmark$ A falta de preparação dos professores para abordar conteúdos de Estatística e Probabilidade nas aulas de matemática propicia, frequentemente, um tratamento escolar inadequado?

\section{2) Objetivos}


$\checkmark$ Investigar com as professoras possa proporcionar para ambas as partes, possibilidades de produzir saberes, que contribuam no desenvolvimento da prática de sala de aula de cada um dos envolvidos.

3) Conclusões e direcionamentos

$\checkmark$ O desejo de partilhar com os alunos o que estava sendo aprendido motivou as professoras a resgatarem um saber-fazer do trabalho docente que fosse possível de reelaborar, já que durante o trabalho de campo não houve oportunidade de sistematizar as discussões conceituais elaboradas em nossos encontros de estudo;

$\checkmark$ Experiência única, pessoal e intransferível que cada uma das professoras vivenciou no processo de aprender noções de probabilidade só seria significativa se partilhada com os alunos e pares;

$\checkmark$ Mudança de postura das professoras-parceiras frente aos encontros, alterando a natureza dos mesmos. O processo de construção de saberes para o trabalho docente, a partir do estudo de noções de Probabilidade, deslocou-se para o âmbito da sala de aula, onde professora e pesquisador comprometeram-se com o desenvolvimento de atividades planejadas e propostas por cada uma delas;

$\checkmark$ Demanda por uma Educação Básica que integre os temas de Estatística e Probabilidade, sendo necessário, também, que sejam criadas condições para que os docentes avaliem as potencialidades pedagógicas de um determinado tema e viabilizem seu tratamento no currículo escolar.

Na tese de Campos (2007) realizada na Universidade Estadual Paulista - UNESP Rio Claro junto ao Programa de Pós-Graduação em Educação Matemática, Área de Concentração em Ensino e Aprendizagem da Matemática e seus Fundamentos FilosóficoCientíficos, orientada pelo Prof. Dra. Maria Lucia Lorenzetti Wodewotzki, “A Educação Estatística: uma investigação acerca dos aspectos relevantes à didática da Estatística em cursos de Graduação" mostramos a problemática, o objetivo principal e os possíveis encaminhamentos para estudos futuros:

1) Problemática 
$\checkmark$ Quais são os principais aspectos que norteiam a Educação Estatística e que podem servir de base para uma definição dos Fundamentos Teóricos da Didática da Estatística?

$\checkmark$ É possível trabalhar os aspectos que norteiam a Educação Estatística em consonância com a estratégia pedagógica da Modelagem Matemática, promovendo atividades educacionais na forma de projetos de ensino?

$\checkmark$ Os preceitos da Educação Crítica e da Educação Matemática Crítica podem ser ligados aos Fundamentos Teóricos da Didática da Estatística na composição desses projetos pedagógicos?

2) Objetivos

$\checkmark$ Estudar teoricamente os fundamentos da didática da Educação Estatística e sua integração com a Educação Crítica e com a Modelagem Matemática;

$\checkmark$ Aplicar essa integração dos fundamentos da didática da Educação Estatística com a Educação Crítica e com a Modelagem Matemática no microcosmo da sala de aula, com o desenvolvimento e a execução de projetos pedagógicos voltados para esse fim;

$\checkmark$ Demonstrar como a integração dos fundamentos da didática da Educação Estatística com a Educação Crítica e com a Modelagem Matemática pode ser obtida, e como é possível fazer a conjugação das teorias didáticas com o dia a dia da sala de aula, enfrentando e superando as tantas dificuldades que a essa empreitada se apresentem.

3) Conclusões e direcionamentos

$\checkmark$ O ser professor e o ser pesquisador se completam e se contrapõem harmonicamente, constituindo o ser educador que constrói a pesquisa e dela se alimenta para devolver aos alunos o produto ensino em uma forma mais dignificante;

$\checkmark$ O ensino e a aprendizagem dessa disciplina nos cursos de Graduação no Brasil e nos demais países do mundo, em geral, encontram severas dificuldades;

$\checkmark$ Há uma significante conjugação de objetivos entre a Educação Crítica, a Modelagem Matemática e os Fundamentos Teóricos da Educação Estatística, 
convergindo para o trabalho com projetos de ensino que estimulam, valorizam e desenvolvem todos esses aspectos comuns.

Ao analisar as teses e dissertações é possível perceber a importância da Estatística tanto no contexto educacional quanto social. A temática abordada demonstra grande inquietação por parte dos pesquisadores no processo ensino-aprendizagem desse conteúdo.

Em todas as pesquisas analisadas, os autores afirmam que na sociedade contemporânea constantemente as pessoas necessitam de conhecimentos básicos de Estatística, especialmente para interpretar e analisar tabelas e gráficos. Tal afirmação vai ao encontro do pensamento dos autores Batanero et al. (1992) ao ressaltarem que, nos últimos anos, o ensino de Estatística vem se desenvolvendo pelo fato de seu valor reconhecido na formação geral do cidadão.

No entanto, embora exista esse reconhecimento, os autores das pesquisas abordadas demonstram preocupação com o docente dos anos iniciais do Ensino Fundamental em relação ao ensino de conceitos elementares de Estatística, pois para a grande maioria dos docentes, este assunto é totalmente novo e torna-se um desafio desenvolver com os estudantes atividades que envolvam aspectos didáticos desse conteúdo.

$\mathrm{Na}$ tese intitulada "A Educação Estatística: uma investigação acerca dos aspectos relevantes à didática da estatística em cursos de graduação”, o autor Campos (2007) ressalta que em relação aos fundamentos teóricos da didática da Estatística, os principais autores que publicaram pesquisas recentes sobre o assunto defendem o desenvolvimento de três importantes competências, quais sejam a literacia, o raciocínio e o pensamento estatístico, sem as quais não seria possível realizar o ensino e a aprendizagem dessa disciplina com sucesso. $\mathrm{O}$ autor ainda propõe um diagrama que utiliza a Figura 1 como base, mas que admite a existência de um conjunto universo da Estatística em seu entorno. 


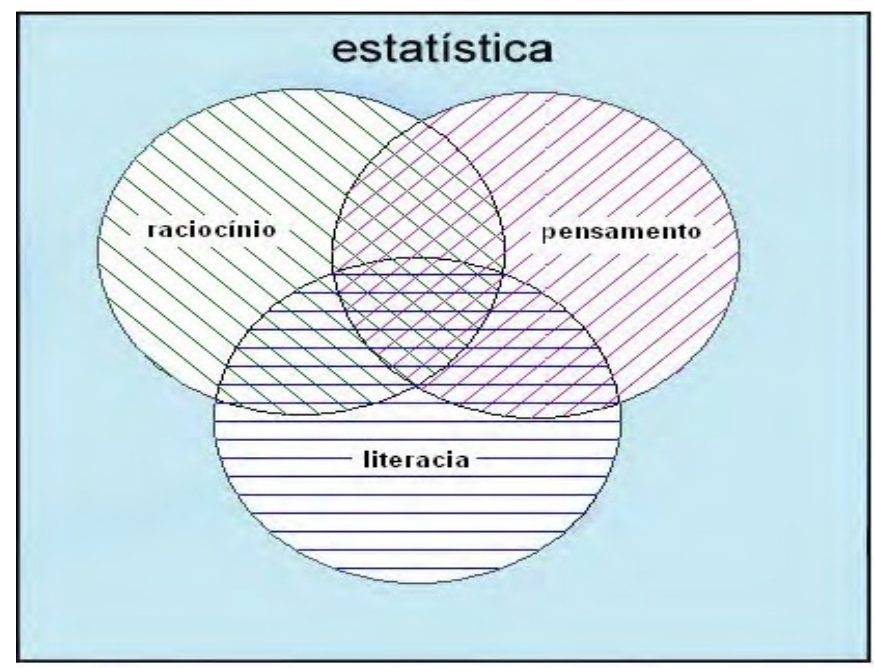

Figura 1- O conjunto universo da Estatística contém elementos que não desenvolvem aspecto algum das três capacidades.

Ainda na perspectiva de Campos (2007), o debate principal é como desenvolver as três capacidades, assim ele sugere algumas ações com o objetivo de auxiliar o professor no trabalho junto aos alunos:

I) Sempre que possível, trabalhar com dados reais.

II) Sempre relacionar os dados ao contexto em que estão inseridos.

III) Sempre orientar os alunos para que interpretem seus resultados.

IV) Permitir que os estudantes trabalhem juntos (em grupo) e que uns critiquem as interpretações de outros, ou seja, favorecer o debate de ideias entre os alunos.

V) Promover julgamentos sobre a validade das conclusões, ou seja, compartilhar com a classe as conclusões e as justificativas apresentadas.

VI) Avaliar constantemente o desenvolvimento das três capacidades em cada domínio da Estatística.

VII) Para cada conteúdo, promover a triangulação:

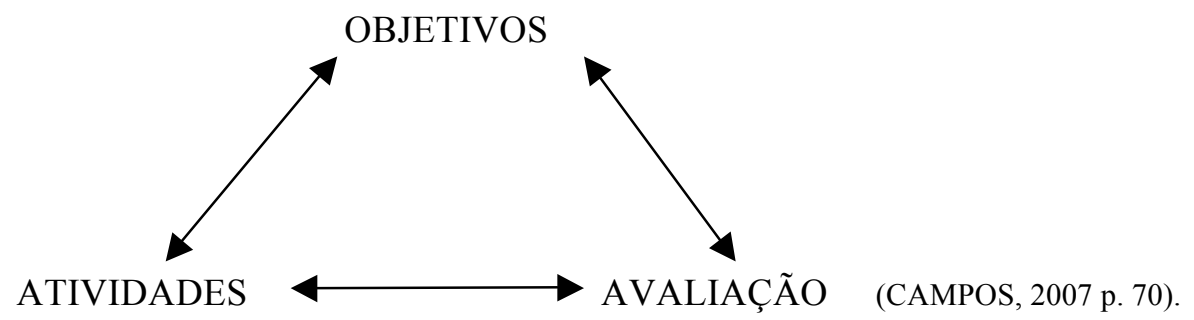

Outro ponto de destaque nos estudos é a questão dos currículos e livros didáticos brasileiros de Matemática recomendados para o Ensino Fundamental ao inserir a Estatística e a Probabilidade desde os anos iniciais. Lopes (1999) investigou e analisou as propostas curriculares de Matemática dos estados de Minas Gerais, São Paulo e Santa Catarina, pois tais estados já tratam o ensino de Estatística e Probabilidade em seus currículos. No que diz respeito a proposta mineira que foi elaborada quase uma década depois de São Paulo, a autora 
considera que tais conteúdos deveriam ser melhor discutidos, apesar do currículo mineiro ser bem estruturado.

Um fato importante que aparece bastante entre os artigos é a utilização das tecnologias. De acordo com Santos (2003), a utilização de computadores é uma realidade em quase todas as áreas de atividade humana, sobretudo no contexto educacional. Os PCN sugerem que o computador seja visto como um recurso didático cada vez mais necessário, uma vez que se trata de um instrumento que traz várias possibilidades ao processo de ensino e aprendizagem de Estatística.

No trabalho de Campos (2007) enfatiza que o docente ao conjugar a teoria e a prática evidencia-se as potencialidades da utilização dos conceitos da Educação Estatística no enfrentamento das dificuldades do ensino de Estatística. O autor reforça que a Estatística não se resume à ciência ou à pesquisa, mas ela está presente na sociedade, na política, no esporte, na mídia, no lazer e, sobretudo na educação.

Para finalizar as ideias propostas nos trabalhos é oportuno recorrer às contribuições de Batanero (2001) que traz uma amplitude da Estatística ao afirmar que

A relação entre o desenvolvimento de um país e o grau em que seu sistema estatístico produz estatísticas completas e confiáveis é clara, porque esta informação é necessária para a tomada de decisões acertadas do tipo econômico, social e político. A educação estatística, não só dos técnicos que produzem essas estatísticas, mas dos profissionais e cidadãos que devem interpretá-las e tomar por sua vez decisões baseadas nessas informações, assim como dos que devem colaborar na obtenção dos dados requeridos, é, portanto, um motor de desenvolvimento (BATANERO, 2001 p. 3).

Nesse sentido, a importância da Estatística só vem crescendo e ainda segundo a autora foi no século XX que houve uma elevada consideração da Estatística como uma das ciências metodológicas essenciais e base do método científico experimental.

\section{Considerações finais}

Este estudo mostrou que a Estatística, por fornecer os procedimentos de coleta e sistematização de informações, permite fazer a interdisciplinaridade entre a Matemática e as demais ciências, tornando-se o fio condutor dos projetos, possibilitando a transversalidade do conhecimento. Todavia os atuais professores que lecionam Matemática na Educação Básica (pedagogos e licenciados) quando estudaram Estatística e Probabilidade, nos cursos de Licenciatura em Pedagogia ou em Matemática, não viram estes conteúdos como objetos a serem ensinados. Por essa razão a pesquisa na Didática da 
Estatística no Brasil é recente, porém cada vez mais crescente. Nesse sentido, fomentar as pesquisas no campo da Estatística é essencial conforme demonstrado nas teses e dissertações deste estudo.

Diante dessa crescente utilização é importante exercer uma reflexão sobre os aspectos relacionados à disciplina Estatística, principalmente desde os anos iniciais do Ensino Fundamental. Os PCN do Ensino Fundamental (Brasil, 1997) sugerem que deve-se ensinar, desde os anos iniciais, a coletar dados, organizá-los em tabelas e gráficos.

Reconhecer tamanha relevância dessa temática é um passo significativo para investir na inserção desse conteúdo e na formação do professor de tal forma que proporcione ao aluno um aprendizado prazeroso e significativo. Diante disso, é oportuno refletir a obra de Freire (1965) intitulada de Educação e liberdade ao enfatizar que a educação teria de ser, acima de tudo, uma tentativa constante de mudança de atitude, de criação de disposições democráticas por meio das quais se substituíssem antigos hábitos de passividade por novos hábitos de participação e de ingerência na realidade do educando. Assim haveria de ser a atitude de uma educação crítica que levasse o homem a uma nova postura diante dos problemas de seu tempo e de seu espaço.

Enfim, registra-se aqui o desejo que este Estado da Arte possa ser uma possível contribuição para o progresso de produções acadêmicas que enfatize a necessidade da abordagem Estatística no processo de ensino-aprendizagem para que o cidadão atue criticamente em seu meio social. Vislumbra-se também que mais docentes passem a compreender esse conteúdo com uma visão consciente e possam colaborar com o preenchimento da lacuna existente de estudos e práticas pedagógicas que contemplem essencialmente da Estatística desde o início do Ensino Fundamental a fim de prolongar aos demais níveis de ensino com sucesso.

\section{Referências}

BATANERO, C. Didáctica de la Estadística. Grupo de Investigación en Educación Estadística, ISBN 84-699-4295-6, Universidad de Granada, Espanha, 2001. Disponível no site <http://www.ugr.es/ batanero/ARTICULOS/didacticaestadistica.zip>. Acesso em: 02 fev. 2014.

BATANERO, C.; GODINO, D.R.; GREEN, P.H.; VALlECILlOS, A Errores y dificultades en la comprensión de los conceptos estadísticos elementales. International Journal of Mathematics Education in Science and Technology, v. 25, n. 4, p. 527-547, 1992. 
BIAJONE, J. Trabalho de Projetos: Possibilidades e Desafios na Formação Estatística do Pedagogo. 2006. 246 f. Dissertação (Mestrado em Educação Matemática) - Universidade Estadual de Campinas, Faculdade de Educação, Programa de Pós-Graduação em Educação, $2006 . \quad$ Disponível em: <http://www.sbem.com.br/gt_12/publicacoes/dissertacoes.htm> Acesso em: 02 fev. 2014.

BRASIL, Ministério da Educação e do Desporto. Secretaria de Educação Fundamental. Parâmetros curriculares nacionais primeiro e segundo ciclos do ensino fundamental: Matemática. Brasília: MEC/SEF, 1997.

CAETANO, S. S. D. Introduzindo a Estatística nas séries iniciais do Ensino Fundamental a partir de material manipulativo: uma intervenção de ensino. 2003. 151 f. Dissertação (Mestrado em Educação Matemática) - Pontifícia Universidade Católica de São Paulo (PUC-SP), Programa de Pós-Graduação em Educação Matemática, 2004. Disponível em: <http://www.sbem.com.br/gt_12/publicacoes/dissertacoes.htm $>$.Acesso em: 02 fev. 2014.

CAMPOS, C. R. A Educação Estatística: uma investigação acerca dos aspectos relevantes à didática da estatística em cursos de graduação. 2007. 242 f. Tese (Doutorado em Educação Matemática) - Universidade Estadual Paulista - UNESP Rio Claro, Programa de Pós-Graduação em Educação Matemática, Área de Concentração em Ensino e Aprendizagem da Matemática e seus Fundamentos Filosófico-Científicos, 2007. Disponível em: <http://www.sbem.com.br/gt_12/publicacoes/teses.htm> Acesso em: 02 fev. 2014.

CAZORLA, I. M. O Ensino de Estatística no Brasil. Artigo disponível no site $<$ http://www.sbem.com.br/gt_12/arquivos/cazorla.htm> Acesso em: 02 fev. 2014.

COSTA, C. A. As concepções dos professores de matemática sobre o uso de modelagem no desenvolvimento do raciocínio combinatório no Ensino Fundamental. 2003. 149 f. Dissertação (Mestrado em Educação Matemática) - Pontifícia Universidade Católica de São Paulo (PUC-SP), Programa de Pós-Graduação em Educação Matemática, 2003. Disponível em: <http://www.sbem.com.br/gt_12/publicacoes/dissertacoes.htm> Acesso em: 02 fev. 2014.

FERREIRA, N. S. A. Pesquisas denominadas estado da arte: possibilidades e limites. Educação e Sociedade, Campinas, v. 1, n.79, p. 257-274, 2002.

FREIRE, P. Educação e liberdade. Rio de Janeiro: Paz e Terra, 1965.

GIL, A. C. Como elaborar projetos de pesquisa. 5. ed. São Paulo: Atlas, 2010.

GONÇALVES, M. C. Concepções de professores e o ensino da Probabilidade na escola básica. 2004. 149 f. Dissertação (Mestrado em Educação Matemática) - Pontifícia 
Universidade Católica de São Paulo (PUC-SP), Programa de Pós-Graduação em Educação Matemática, $2004 . \quad$ Disponível em: <http://www.sbem.com.br/gt_12/publicacoes/dissertacoes.htm> Acesso em: 02 fev. 2014.

GONZÁLEZ REY, F. Lo cualitativo y lo cuantitativo en la investigación de la psicología social. Psicologia \& Sociedade, São Paulo, v. 10, n. 2, p. 32-52, 1998.

LOPES, C. A. E. A Probabilidade e a Estatística no Currículo de Matemática do Ensino Fundamental Brasileiro. In: Atas da Conferência Internacional "Experiências e Expectativas do Ensino de Estatística - Desafios para o Século XXI" - Florianópolis, Santa Catarina, Brasil - 20 a 23 de Setembro de 1999.

LOPES, C. A. E. O conhecimento profissional dos professores e suas relações com estatística e probabilidade na educação infantil. 2003. 281 f. Tese (Doutorado em Educação) - Universidade Estadual de Campinas, Faculdade de Educação, Programa de Pós-Graduação em Educação, 2003. Disponível em: <http://www.sbem.com.br/gt_12/publicacoes/teses.htm> Acesso em: 02 fev. 2014.

OLIVEIRA, P. C. O processo de aprender noções de probabilidade e suas relações no cotidiano das séries iniciais do Ensino Fundamental: uma história de parceria. Tese (Doutorado em Educação) - Universidade Estadual de Campinas, Faculdade de Educação, Programa de Pós-Graduação em Educação, 2003. Disponível em: $<$ http://www.sbem.com.br/gt_12/publicacoes/teses.htm> Acesso em: 02 fev. 2014.

SANTOS, S. S. A formação do professor não especialista em conceitos elementares do bloco tratamento da informação. 2003. 149 f. Dissertação (Mestrado em Educação Matemática) - Pontifícia Universidade Católica de São Paulo (PUC-SP), Programa de PósGraduação em Educação Matemática, 2003. Disponível em: $<$ http://www.sbem.com.br/gt_12/publicacoes/teses.htm> Acesso em: 02 fev. 2014.

SELVA, A. C. V. Gráficos de barras e materiais manipulativos: analisando dificuldades e contribuições de diferentes representações no desenvolvimento da conceptualização matemática em crianças de seis a oito anos. 2003. $225 \mathrm{f}$. Tese (Doutorado em Psicologia) - Universidade Federal de Pernambuco, Programa de PósGraduação em Psicologia - área de concentração: Psicologia Cognitiva Disponível em: $<$ http://www.sbem.com.br/gt_12/publicacoes/teses.htm> Acesso em: 02 fev. 2014.

SBEM. Sociedade Brasileira de Educação Matemática. Disponível no site $<$ http://www.sbem.com.br> Acesso em: 02 fev. 2014.

RECEBIDO EM: 01/10/2015. APROVADO EM: 23/02/2016. 